\title{
Efficacy of Arteether Against Theileriosis in Cattle
}

\author{
Tikeshwar Khawale", M.F.M.F. Siddiqui ${ }^{1}$, Sudhirkumar Borikar ${ }^{1}$, Meera Sakhare ${ }^{2}$ and Tawheed Shafi $^{2}$ \\ ${ }^{1}$ Department of Veterinary Clinical Medicine, Ethics and Jurisprudence, College of Veterinary and Animals Sciences, MAFSU, \\ Parbhani (M.S.) INDIA \\ ${ }^{2}$ Department of Veterinary Epidemiology and Preventive Medicine, MAFSU, Parbhani (M.S.) INDIA \\ *Corresponding author: TS Khawale; E-mail: tkhawale17@gmail.com
}

Received: 18 Sept., 2019

Revised: 10 Oct., 2019

Accepted: 20 Oct., 2019

\begin{abstract}
The present study was done with the objective of comparative efficacy of arteether and buparvaquone against theileriosis in cattle. Total 67 cattle suspected for theileriosis were screened on the basis of clinical and blood smear examination. Group I ( $\mathrm{n}=6)$ was treated with Inj. buparvaquone @ $2.5 \mathrm{mg} / \mathrm{kg}$ body weight once and Group II (n=6) was treated with Inj. arteether@5 mg/ $\mathrm{kg}$ body weight intramuscularly for three consecutive days. Rectal temperature, heart rate and respiration rate were significantly increased before treatment and in both the groups after treatment showed significant improvement. Haematological parameters showed significant decreased in Hb, PCV, TEC, TLC and neutrophil and significant increase in lymphocytes, monocytes and eosinophil. Non significant difference in basophil count was observed. After treatment, significant improvement was observed in mean hemoglobin, PCV, TEC, TLC, neutrophil, lymphocyte and eosinophil. Non significant improvement was observed in monocyte and basophil count. Present study revealed percent efficacy of arteether was $66.66 \%$ and buparvaquone $100 \%$.
\end{abstract}

Keywords: Arteether, Theileriosis, Buparvaquone, Cattle, Theileria annulata

Theileriosis is a tick borne disease caused by Theileria annulata and transmitted by genus Hyalomma spp.. Bovine tropical theileriosis is most prevalent and economically important disease of dairy herd which cause production loss. Theileria annulata is an intracellular parasite that infects both wild and domestic bovidae all over the world and some species also infect small ruminants. They are transmitted with Ixodid ticks and have complex life cycle in vertebrate as well as invertebrate hosts, (OIE, 2014). The disease occurs when there is more tick activity, mainly in summer and rainy seasons. The overall occurrence of theilerioisis in cattle is $22.38 \%$ (Khawale et al., 2019). A single tick can cause deadly infection as it generally contains countless sporozoites in its salivary glands. The incubation period of theileriosis is 4 to 14 days after attachment of the tick on the host body.

Buparvaquone is the only drug which is used for all type of theileriosis as treatment and prophylaxis. It is a second-generation parvaquone-related hydroxyl- naphthoquinone derivative acts by binding to cytochrome b (cyt-b) inhibiting the electron transport chain in the parasite (Mhadhbi et al., 2015). Recent reports regarding development of resistance against buparvaquone and lack of cost effective treatment in theileriosis and the published utility of Arteether in different haemoprotozoan infection, the present research work was designed.

Arteether is a semi-synthetic artemisinin derivative, a natural product of the Chinese plant Artemisia annua. It is a well-known medicinal plant that has been utilized for a number of purposes, including malaria, for centuries. It is a fast acting blood schizonticidal drug specifically meant for the treatment of chloroquine-resistant Plasmodium falciparum malaria and cases of cerebral malaria (Okunlola et al., 2013). Several semisynthetic derivatives of artemisinin have been used increasingly over the past

How to cite this article: Khawale, T., Siddiqui, M.F.M.F., Borikar, S. Sakhare, M. and Shafi, T. (2019). Efficacy of Arteether against Theileriosis in cattle. J. Anim. Res., 9(6): 883-888. 
two decades as antimalarials. Artemisinin is the active ingredient of the Chinese herb 'qinghaosu' (Artemisia annua) that was traditionally used for treating fevers.

\section{MATERIALS AND METHODS}

The animals were selected from areas like Teaching Veterinary Clinical Complex, Instructional Livestock Farm Complex, COVAS, Parbhani and nearby villages from Parbhani District, Maharashtra, India. The study was carried out for six months from January - June 2019. Total 67 suspected cattle were examined in different age, sex and breed randomly belonging to different localities in Parbhani district. The screening was done based on the clinical signs like high body temperature, enlargement of lymph nodes, conjunctiva petechiae, tick infestation and haemoglobin level more than $6 \mathrm{~g} / \mathrm{dl}$. Total 12 positive cases of theileriosis were examined of clinical, haematological and biochemical studies.

Clinical examination includes recording of rectal temperature by clinical thermometer, heart rate by auscultating heart for 1 minute and respiration rate by holding back hand in front of nostrils and the air current was counted for period of 1 minute. The animals were examined for high temperature, enlargement of lymph nodes, conjunctiva petichie and presence of ticks on animal's body.

Blood samples from theileriosis affected cattle for hematological analysis from jugular vein in a clean, sterile tube containing Ethylene Diamine Tetra Acetic Acid (EDTA) at the rate of $2 \mathrm{mg} / \mathrm{ml}$ of blood. For diagnosis of theileriosis, blood smear was prepared from the blood taken from ear tip at the height of temperature. Blood samples from jugular vein were collected at day $0^{\text {th }}$, day $7^{\text {th }}$ and day $21^{\text {st }}$ for haematological investigation. Twelve clinically positive cases of theileriosis were distributed in two equal groups $(n=6)$. Group I was treated with inj. buparvaquone@2.5 mg/kg body weight once and Group II was treated with inj. arteether @ $5 \mathrm{mg} / \mathrm{kg}$ body weight intramuscularly for three consecutive days.

\section{RESULTS AND DISCUSSION}

The clinical parameters in treatment group I treated with Inj Buparvaquone and group II treated with Inj Arteether showed significant improvement in rectal temperature $\left({ }^{\circ} \mathrm{F}\right)$ and heart rate on day $7^{\text {th }}$ and day $21^{\text {st }}$ post treatment as compared to day ' 0 ' before treatment. Mean respiration rate in group I was non significantly decreased on day 7 but significant decreased on day $21^{\text {st }}$ after treatment as compared to day ' 0 ' before treatment and in group II, mean respiration rate was significantly decreased on day $7^{\text {th }}$ and $21^{\text {st }}$ post treatment as compared to $0^{\text {th }}$ day before treatment. The clinical parameters showings various alterations in buparvaquone and arteether treated groups before treatment and after different intervals is depicted in table 1 .

The analysis of variance revealed significant variation in pooled mean of rectal temperature $\left({ }^{\circ} \mathrm{F}\right)$ between both groups (I and II) and pooled mean between periods showed significant decrease on $7^{\text {th }}$ and $21^{\text {st }}$ day post treatment as compared to ' 0 ' day before treatment. However, the analysis of variance revealed non significant variation in pooled mean of heart rate and respiration rate between both groups (I and II). The pooled mean of heart rate between periods showed significant decrease in day $7^{\text {th }}$ and $21^{\text {st }}$ post treatment as compared to $0^{\text {th }}$ day before treatment.

Haematological observations revealed the treatment group I and group II showed non significant but apparent improvement in haemoglobin concentration at $7^{\text {th }}$ day and significant improvement at $21^{\text {st }}$ day post treatment. The packed cell volume in treatment group I showed non significant but apparent improvement at $7^{\text {th }}$ day and significant improvement at $21^{\text {st }}$ day post treatment. However, in group II the mean PCV values were increased non significantly but apparent improvement observed on $7^{\text {th }}$ day and $21^{\text {st }}$ day post treatment as compared to ' 0 ' day before treatment. Similar findings were reported by Nayak et al. (2018) and Siddiqui et al. (2017).

The analysis of variance revealed non-significant variation in pooled mean of haemoglobin and PCV between both groups (I and II). The pooled mean of haemoglobin concentration of periods showed non--significant but apparent increase in haemoglobin concentration on $7^{\text {th }}$ day post treatment and showed significant increase on $21^{\text {st }}$ day post treatment as compared to ' 0 ' day before treatment.

The treatment group I showed non-significant but apparent increase in TEC values on $7^{\text {th }}$ day and significant increase on $21^{\text {st }}$ day post treatment as compared to ' 0 ' day before treatment. The analysis of variance revealed non significant variation in pooled mean of total erythrocyte 
Table 1: Clinical parameters in Buparvaquone and Arteether treated groups before treatment and at different intervals after treatment

\begin{tabular}{cccccc}
\hline Clinical parameters & & $\mathbf{0}^{\text {th }}$ day & ${7^{\text {th }} \text { day }}$ & $\mathbf{2 1}^{\text {st }}$ day & Pooled mean \\
\hline \multirow{4}{*}{ Rectal temperature } & Group-I & $105.47^{\mathrm{b}} \pm 0.37$ & $102.05^{\mathrm{a}} \pm 0.22$ & $102.05^{\mathrm{a}} \pm 0.12$ & $\mathbf{1 0 3 . 1 9} \pm \mathbf{1 . 1 4}$ \\
& Group-II & $106.37^{\mathrm{b}} \pm 0.29$ & $103.03^{\mathrm{a}} \pm 0.25$ & $102.55^{\mathrm{a}} \pm 0.12$ & $\mathbf{1 0 3 . 9 8} \pm \mathbf{1 . 2 0}$ \\
& Pooled mean & $\mathbf{1 0 5 . 9 2}^{\mathrm{B}} \pm \mathbf{0 . 4 5}$ & $\mathbf{1 0 2 . 5 4}^{\mathbf{A}} \pm \mathbf{0 . 4 9}$ & $\mathbf{1 0 2 . 3 0}^{\mathbf{A}} \pm \mathbf{0 . 2 5}$ & \\
& Group-I & $80.83^{\mathrm{b}} \pm 5.12$ & $67.83^{\mathrm{a}} \pm 3.32$ & $69.50^{\mathrm{a}} \pm 1.02$ & $\mathbf{7 2 . 7 2} \pm \mathbf{4 . 0 8}$ \\
Heart rate & Group-II & $77.83^{\mathrm{b}} \pm 3.30$ & $71.33^{\mathrm{a}} \pm 0.80$ & $69.83^{\mathrm{a}} \pm 1.01$ & $\mathbf{7 3 . 0 0} \pm \mathbf{2 . 4 5}$ \\
& Pooled mean & $\mathbf{7 9 . 3 3}^{\mathbf{B}} \pm \mathbf{1 . 5 0}$ & $\mathbf{6 9 . 5 8}^{\mathbf{A}} \pm \mathbf{1 . 7 5}$ & $\mathbf{6 9 . 6 6}^{\mathbf{A}} \pm \mathbf{0 . 1 7}$ & \\
& Group-I & $48.33^{\mathrm{bc}} \pm 6.27$ & $29.33^{\mathrm{ab}} \pm 3.25$ & $25.17^{\mathrm{a}} \pm 0.94$ & $\mathbf{3 4 . 2 8} \pm \mathbf{7 . 1 3}$ \\
Respiration rate & Group-II & $61.17^{\mathrm{bc}} \pm 8.29$ & $31.50^{\mathrm{ab}} \pm 4.38$ & $27.00^{\mathrm{a}} \pm 1.59$ & $\mathbf{3 9 . 8 9} \pm \mathbf{1 0 . 7 2}$ \\
& Pooled mean & $\mathbf{5 4 . 7 5}^{\mathbf{B}} \pm \mathbf{6 . 4 2}$ & $\mathbf{3 0 . 4 2}^{\mathbf{A}} \pm \mathbf{1 . 0 8}$ & $\mathbf{2 6 . 0 8}^{\mathbf{A}} \pm \mathbf{0 . 9 2}$ & \\
\hline
\end{tabular}

Table 2: Haematological parameters in Buparvaquone and Arteether treated groups before treatment and at different intervals after treatment

\begin{tabular}{|c|c|c|c|c|c|}
\hline $\begin{array}{c}\text { Haematological } \\
\text { parameters }\end{array}$ & & $0^{\text {th }}$ day & $7^{\text {th }}$ day & $21^{\text {st }}$ day & Pooled mean \\
\hline \multirow{3}{*}{$\mathrm{Hb}$} & Group-I & $6.68^{a} \pm 0.17$ & $6.70^{\mathrm{a}} \pm 0.16$ & $7.25^{b} \pm 0.15$ & $6.88 \pm 0.18$ \\
\hline & Group-II & $6.63^{\mathrm{a}} \pm 0.16$ & $6.73^{\mathrm{a}} \pm 0.16$ & $7.23^{b} \pm 0.11$ & $6.87 \pm 0.18$ \\
\hline & Pooled mean & $6.66^{\mathrm{A}} \pm 0.02$ & $6.72^{\mathrm{A}} \pm 0.02$ & $7.24^{\mathrm{B}} \pm 0.01$ & \\
\hline \multirow{3}{*}{ PCV } & Group-I & $19.13^{\mathrm{a}} \pm 0.77$ & $20.07^{\mathrm{a}} \pm 0.72$ & $22.58^{b} \pm 0.19$ & $20.59 \pm 1.03$ \\
\hline & Group-II & $19.12^{\mathrm{a}} \pm 0.89$ & $20.43^{\mathrm{a}} \pm 1.01$ & $21.87^{\mathrm{a}} \pm 0.81$ & $20.47 \pm 0.79$ \\
\hline & Pooled mean & $19.12^{\mathrm{A}} \pm 0.01$ & $20.25^{\mathrm{A}} \pm 0.18$ & $22.22^{\mathrm{B}} \pm 0.38$ & \\
\hline \multirow{3}{*}{ TEC } & Group-I & $3.98^{\mathrm{ab}} \pm 0.39$ & $4.10^{\mathrm{ab}} \pm 0.41$ & $4.56^{b} \pm 0.33$ & $4.22 \pm 0.18$ \\
\hline & Group-II & $3.55^{\mathrm{a}} \pm 0.19$ & $3.72^{\mathrm{ab}} \pm 0.19$ & $4.14^{\mathrm{ab}} \pm 0.23$ & $3.80 \pm 0.17$ \\
\hline & Pooled mean & $\mathbf{3 . 7 6} \pm 0.21$ & $\mathbf{3 . 9 1} \pm 0.19$ & $\mathbf{4 . 3 6} \pm 0.22$ & \\
\hline \multirow{3}{*}{ TLC } & Group-I & $7.42^{\mathrm{a}} \pm 0.25$ & $9.30^{\mathrm{a}} \pm 0.28$ & $10.33^{b} \pm 0.76$ & $9.02 \pm 0.85$ \\
\hline & Group-II & $7.95^{\mathrm{a}} \pm 0.84$ & $9.21^{\mathrm{a}} \mathrm{c} 1.16$ & $10.35^{b} \pm 1.81$ & $9.17 \pm 0.69$ \\
\hline & Pooled mean & $7.68^{A} \pm 0.27$ & $9.26^{A} \pm 0.04$ & $10.34^{B} \pm 0.01$ & \\
\hline
\end{tabular}

count between both groups (I and II) and between periods showed apparent but non significant increase on $7^{\text {th }}$ day and $21^{\text {st }}$ day post treatment as compared to $0^{\text {th }}$ day before treatment. The treatment group I and group II showed non significant but apparent improvement in total leucocyte count after $7^{\text {th }}$ day and significant improvement $21^{\text {st }}$ day post treatment as compared to day ' 0 ' day before treatment. The analysis of variance revealed non significant variation in pooled mean of total leucocyte count between both groups (I and II). The pooled mean of TLC in periods showed non significant but apparent increase on $7^{\text {th }}$ day and significant increase on $21^{\text {st }}$ day post treatment as compared to ' 0 ' day before treatment. The haematological parameters showings various alterations in buparvaquone and arteether treated groups before treatment and after different intervals is depicted in table 2 .

Differential leucocyte count showed various alterations in treatment group I treated with Inj. buparvaquone and group II treated with Inj. arteether. The neutrophil count showed significant improvement in treatment group I on $7^{\text {th }}$ day and $21^{\text {st }}$ day post treatment as compared to day ' 0 ' before treatment. In group II, significant improvement was observed on day $7^{\text {th }}$ and day $21^{\text {st }}$ after treatment as compared to ' 0 ' day before treatment. Pooled mean of neutrophil between periods showed significant increase in values on $7^{\text {th }}$ and $21^{\text {st }}$ day post treatment as compared to $0^{\text {th }}$ day before treatment. 
The treatment group I and group II showed significant improvement in lymphocyte count on $7^{\text {th }}$ day and $21^{\text {st }}$ day post treatment as compared to ' 0 ' day before treatment. Pooled mean of lymphocyte between periods showed significant improvement after $7^{\text {th }}$ and $21^{\text {st }}$ day post treatment as compared to $0^{\text {th }}$ day before treatment. The treatment group I showed non significant but apparent improvement in monocyte and eosinophil count after $7^{\text {th }}$ day and $21^{\text {st }}$ day post treatment as compared to ' 0 ' day before treatment. In group II, significant improvement observed on day $7^{\text {th }}$ and day $21^{\text {st }}$ after treatment as compared to ' 0 ' day before treatment. Pooled mean of monocytes between periods showed non significant variation on $7^{\text {th }}$ and $21^{\text {st }}$ day post treatment as compared to ' 0 ' day before treatment and pooled mean of eosinophil count between periods showed significant improvement after $7^{\text {th }}$ day and $21^{\text {st }}$ day post treatment as compared to ' 0 ' day before treatment. The analysis of variance revealed non significant variation in pooled mean of basophil count in both the treatment groups and pooled mean of basophil between periods on $7^{\text {th }}$ and $21^{\text {st }}$ day post treatment as compared ' 0 ' day before treatment. The differential leucocyte count showings various alterations in buparvaquone and arteether treated groups before treatment and after different intervals is depicted in table 3 .
Analysis of variance revealed non significant variation in pooled mean of neutrophil, lymphocyte, monocyte, eosinophil and basophil between groups indicating the arteether has at par efficacy as compared to buparvaquone.

Clinical and haematological studies revealed that Arteether has at par efficacy as compared to Buparvaquone in theileriosis affected cattle.

In present research work, out of 6 animals treated with Inj. arteether @ $5 \mathrm{mg} / \mathrm{kg}$ B.W. intramuscularly, four animals recovered clinically after $21^{\text {st }}$ day post treatment contributing percent efficacy of $66.66 \%$. However, Inj. buarvaquone@2.5 mg/kg B.W. deep intramuscularly given to one of the treatment group which showed 100.00 $\%$ efficacy in theileriosis affected cattle.

The rise in rectal temperature might be due to liberation of endogenous progeny because of cellular lysis and high level of parasitemia which leads to the stimulation of thermoregulatory centre in hypothalamus (Al-Emarah et al., 2012). However, the rise in heart rate and respiration rate might be due to the cytokines like, tumor necrosis factor- $\alpha$ and interleukins (TNF- $\alpha$, IL-1 and IL-6) produced by infected mononuclear cells which are responsible for the diverse clinical symptoms of tropical theileriosis (Kacchawa et al., 2016).

Table 3: Differential leucocyte count in Buparvaquone and Arteether treated groups before treatment and at different intervals after treatment

\begin{tabular}{|c|c|c|c|c|c|}
\hline DLC & & $0^{\text {th }}$ day & $7^{\text {th }}$ day & $21^{\text {st }}$ day & Pooled mean \\
\hline \multirow{3}{*}{ Neutrophil } & Group-I & $22.00^{a} \pm 1.73$ & $31.50^{b} \pm 3.08$ & $37.33^{b} \pm 3.10$ & $30.28 \pm 0.18$ \\
\hline & Group-II & $22.17^{\mathrm{a}} \pm 2.98$ & $34.00^{b} \pm 2.12$ & $43.00^{\mathrm{c}} \pm 1.59$ & $33.06 \pm 0.17$ \\
\hline & Pooled mean & $22.08^{\mathrm{A}} \pm 0.21$ & $32.75^{\mathrm{B}} \pm 0.19$ & $40.17^{\mathrm{C}} \pm 0.22$ & \\
\hline \multirow{3}{*}{ Lymphocyte } & Group-I & $71.00^{c} \pm 1.63$ & $59.17^{b} \pm 1.62$ & $55.33^{\mathrm{a}} \pm 2.23$ & $61.83 \pm 4.75$ \\
\hline & Group-II & $68.83^{c} \pm 2.98$ & $59.67^{b} \pm 2.01$ & $52.00^{\mathrm{a}} \pm 1.65$ & $60.17 \pm 4.86$ \\
\hline & Pooled mean & $69.92^{C} \pm 1.08$ & $59.42^{\mathrm{B}} \pm 0.25$ & $53.67^{\mathrm{A}} \pm 1.66$ & \\
\hline \multirow{3}{*}{ Monocyte } & Group-I & $4.83^{\mathrm{a}} \pm 0.30$ & $4.00^{\mathrm{a}} \pm 0.25$ & $4.67^{\mathrm{a}} \pm 0.33$ & $4.50 \pm 0.25$ \\
\hline & Group-II & $5.67^{b} \pm 1.33$ & $4.33^{\mathrm{a}} \pm 0.33$ & $3.83^{\mathrm{a}} \pm 0.16$ & $4.61 \pm 0.55$ \\
\hline & Pooled mean & $5.25 \pm 0.42$ & $4.17 \pm 0.17$ & $4.25 \pm 0.42$ & \\
\hline \multirow{3}{*}{ Eosinophil } & Group-I & $2.17^{\mathrm{a}} \pm 0.16$ & $1.83^{\mathrm{a}} \pm 0.16$ & $2.00^{\mathrm{a}} \pm 0.44$ & $2.00 \pm 0.83$ \\
\hline & Group-II & $2.83^{b} \pm 0.30$ & $2.17^{\mathrm{a}} \pm 0.30$ & $1.17^{\mathrm{a}} \pm 0.16$ & $2.06 \pm 0.50$ \\
\hline & Pooled mean & $2.50^{B} \pm 0.33$ & $2.00^{\mathrm{A}} \pm 0.17$ & $1.58^{\mathrm{A}} \pm 0.41$ & \\
\hline \multirow{3}{*}{ Basophil } & Group-I & $0.00 \pm 0.00$ & $0.00 \pm 0.00$ & $0.17 \pm 0.17$ & $0.06 \pm 0.06$ \\
\hline & Group-II & $0.17 \pm 0.17$ & $0.17 \pm 0.17$ & $0.00 \pm 0.00$ & $0.11 \pm 0.06$ \\
\hline & Pooled mean & $0.08 \pm 0.09$ & $0.08 \pm 0.09$ & $0.08 \pm 0.09$ & \\
\hline
\end{tabular}


The decline in haemoglobin concentration has been attributed to the toxic metabolites of Theileria spp. which is having harmful effect on bone marrow as they hamper erythtropoeisis. Persistent loss of blood caused by continuous blood sucking ticks which play an important role in haemoglobin loss, Somu et al., (2017) and AlEmarah et al., (2012). The decrease in packed cell volume (\%) might be due to presence of reticulocytes in the blood smear of the infected animals revealing increase in activity of the bone marrow by natural infection of $T$. annulata (Tuli et al., 2015). The decrease in total erythrocyte count might be due to intraerythrocytic piroplasms or an autoimmune reaction although it may also be attributed to erythro-phagocytosis rather than a parasite induced lysis. TNF- $\alpha$ released by infected cells are required for causing suppression of haemopoetic progenitors and reduction in $\mathrm{RBC}$ production. It reduces life span of RBCs resulting into anaemia (Tuli et al., 2015) and decrease in total leucocyte count might be due to persistence harmful effect of toxic metabolites of Theileria on the haemopoietic organ especially bone marrow and their interference with the process of leucogenesis (Hussein et al., 2007).

The decrease in neutrophil percentage might be attributed to persistent harmful effect of toxic metabolites of Theileria spp. on hemopoietic organs specially bone marrow and there interference with the process of leucogenesis and due to proliferation of lymphocytes in the lymphoid organ as defensive response to invading parasite (Al-Emarah et al., 2012). The increase in lymphocyte percentage might be due to persistent harmful effect of toxic metabolites of Theileria on hemopoietic organs specially bone marrow and there interference with the process of leucogenesis and proliferation of lymphocytes in the lymphoid organ as defensive response to invading parasite. The lymphocytosis might be due to intralymphocytic Theileria parasites transforming the host cell, leading to clonal growth of lymphocytes (Ganguly et al., 2015). The change in monocyte percentage might be attributed to persistent harmful effect of Theileria spp. on hemopoietic organs specially bone marrow and there interference with the process of leucogenesis and due to proliferation of lymphocytes in the lymphoid organ as defensive response to invading parasite (Hussein et al., 2007). The increase in eosinophil count might be due to most of the animals in both the groups were tick infested, relating to hypersensitivity exhibiting eosinophilia (Tuli et al., 2015).

\section{CONCLUSION}

Inj Arteether has showed at par efficacy as compared to Inj Buparvaquone in respect to clinical parameters and hematological parameters. In respect to treatment Inj arteether revealed percent efficacy of $66.66 \%$ and Inj buparvaquone showed $100 \%$. However, buparvaquone was found to have higher efficacy as compared to arteether.

\section{REFERENCES}

Al-Emarah, G.Y.A. 2012. Clinical, haematological and biochemical Study to cattle naturally infected with Theileria annulata in North of Basrah Province. Al-Qadisiya J. Vet. Med. Sci., 11(1): 54-62.

Ganguly A., Bhanot, V., Bisla, R., Ganguly, I., Singh, H. and Chaudhri, S. 2015. Hematobiochemical alterations and direct blood polymerase chain reaction detection of Theileria annulata in naturally infected crossbred cows. Vet. World., 8(1): 24-28.

Hussein, A.H, Mohammed, N.A.E. and Mohammed, H.K. 2007. Theileriosis and babesiosis in cattle, haemogram and some biochemical parameters. Proceedings of XIII International Congress of ISAH, June17-21. Tartu, Estonia., 143-150.

Kachhawa, J.P., Kumar, S., Sharma, A., Singh, A.P. and Ahuja, A. 2016. Studies on alterations of clinical and hematobiochemical parameters before and after treatment in calves naturally infected with theileriosis. Vet.. World., 9(12): 13811385.

Khawale, T.S., Siddiqui, M.F.M.F., Borikar, S.T., Sakhare, M.P., Rajurkar, S.R., Chigure, G.M. and Shafi, T.A. 2019. Study of occurrence of theileriosis in cattle from Parbhani district, Maharashtra, India. Pharma Innovation, 8(9): 171-173

Mhadhbi, M., Chaouch, M., Chaouch, K., Darghouth, M.A. and, BenAbderrazak, S. 2015. Sequence polymorphism of cytochrome $\mathrm{b}$ gene in Theileria annulata tunisian isolates and its association with buparvaquone treatment failure. Plos One., 10(6): 1-11.

Nayak, S.M., Senapati, S.K., Samal, P., Sethy, K., Meher, S., Swain, P., Sahoo, P.R. and Das, M.R. 2018. Therapeutic management of oxidative stress in cattle, naturally affected with bovine tropical theileriosis by vitamin e and selenium. Pharma Innovation., 7(4): 1141-1145.

OIE 2014. Manual of Diagnostic Tests and Vaccines for Terrestrial Animals. $7^{\text {th }}$ ed., Vol. 1-2. Office International Des Epizooties, Paris.

Okunlola, A.I., Okunlola, C.K., Okani, C.O., Adewole, O.S., Ojo, S.K., Abiodun, A.A., Bejide, R.A. and Ojewole, A.O. 2013. Histological and biochemical effects of arteether ${ }^{\mathrm{TM}}$ on the 
liver of wistar rats. Afr. J. Tradit. Compl. Altern. Med., 10(4): 155-160.

Siddiqui, M.F.M.F., Waghmare, S.P., Mode, S.G., Rekhate, D.H., Kolte, S.W., Hajare, S.W. and Ali, S.S. 2017. Phytopharmacological study and therapeutic efficacy of Calotropis procera (flower) against theileriosis in cattle. J. Ani. Res., 4(7): 757-762.

Somu, Y., Mani, S., Muthusamy, R., Mani, S., Thangamani, A., Konappan, J., Muthusamy, V., Subbaih, K.K. and Palanisamy, S. 2017. Haemato- biochemical and electrolyte alterations in naturally occurring Theileria associated bovine anaemia (taba). J. Anim. Health Prod., 5(2): 64-67.
Tuli, A., Singla, L.D., Sharma, A., Bal, M.S., Filia, G. and Kaur, P. 2015. Molecular epidemiology, risk factors and hematochemical alterations induced by Theileria annulata in bovines of Punjab (India). Acta Parasitologica., 60(3): 378390. 